\title{
SHORT REPORT: POSSIBLE CRYPTOSPORIDIUM MURIS INFECTION IN HUMANS
}

\section{TATSUYA KATSUMATA, DANIEL HOSEA, IGN GDE RANUH, SHOJI UGA, TETSUO YANAGI, AND SHIGERU KOHNO}

Department of Parasitology and Department of Protozoology, Institute of Tropical Medicine, Nagasaki University, Nagasaki,

Japan; Tropical Disease Research Center, Airlangga University, Surabaya, Indonesia; Department of Medical Technology, Faculty of Health Science, Kobe University School of Medicine, Kobe, Japan: Second Department of Internal Medicine, Nagasaki University School of Medicine, Nagasaki, Japan

Abstract. Oocysts of cryptosporidia whose morphology resembled that of Cryptosporidium muris were found in the stool of 2 healthy girls in Surabaya, Indonesia. The oocysts were predominantly oval and measured $7.75 \pm 0.17$ $\times 5.55 \pm 0.13 \mu \mathrm{m}$ (mean $\pm \mathrm{SD}$ ). The number of oocysts excreted were more than $10^{5}$ per gram of stool. The oocysts were well stained with fluorescein-conjugated monoclonal antibody to Cryptosporidium. The specimens from both girls containing the oocysts showed a positive result by the polymerase chain reaction (PCR) using primers specific for the genus Cryptosporidium, but a negative result by the PCR using primers specific for C. parvum. The 2 girls passed oocysts for 5 and 6 days, respectively. They did not complain of any symptoms during the passage of oocysts.

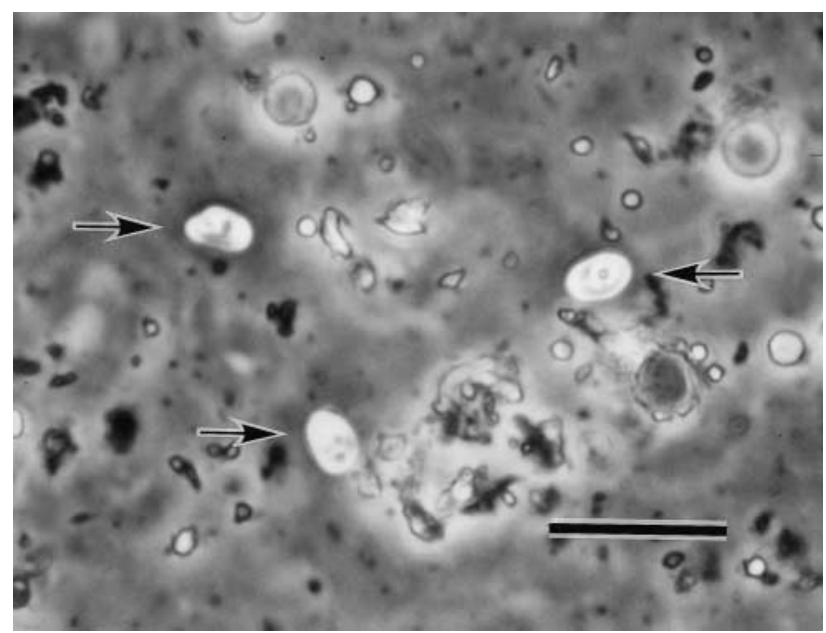

FIGURE 1. Phase-contrast microscopy of Cryptosporidium oocysts (arrows) from a healthy girl. The oocysts appear bright and birefringent, contain black residual bodies, are oval, and measure $7.75 \pm 0.17 \times 5.55 \pm 0.13 \mu \mathrm{m}($ mean $\pm \mathrm{SD}) . \mathrm{Bar}=20 \mu \mathrm{m}$.

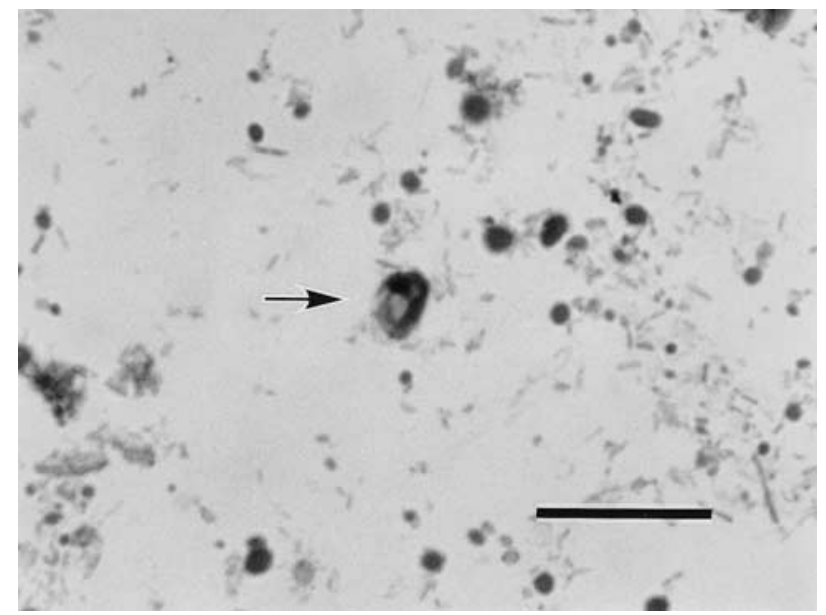

FIGURE 2. Bright-field microscopy of a Cryptosporidium oocyst (arrow) from a healthy girl. The oocyst contains sporozoites and a residue of numerous small granules (Kinyoun-modified acid-fast stain, bar $=20 \mu \mathrm{m})$.
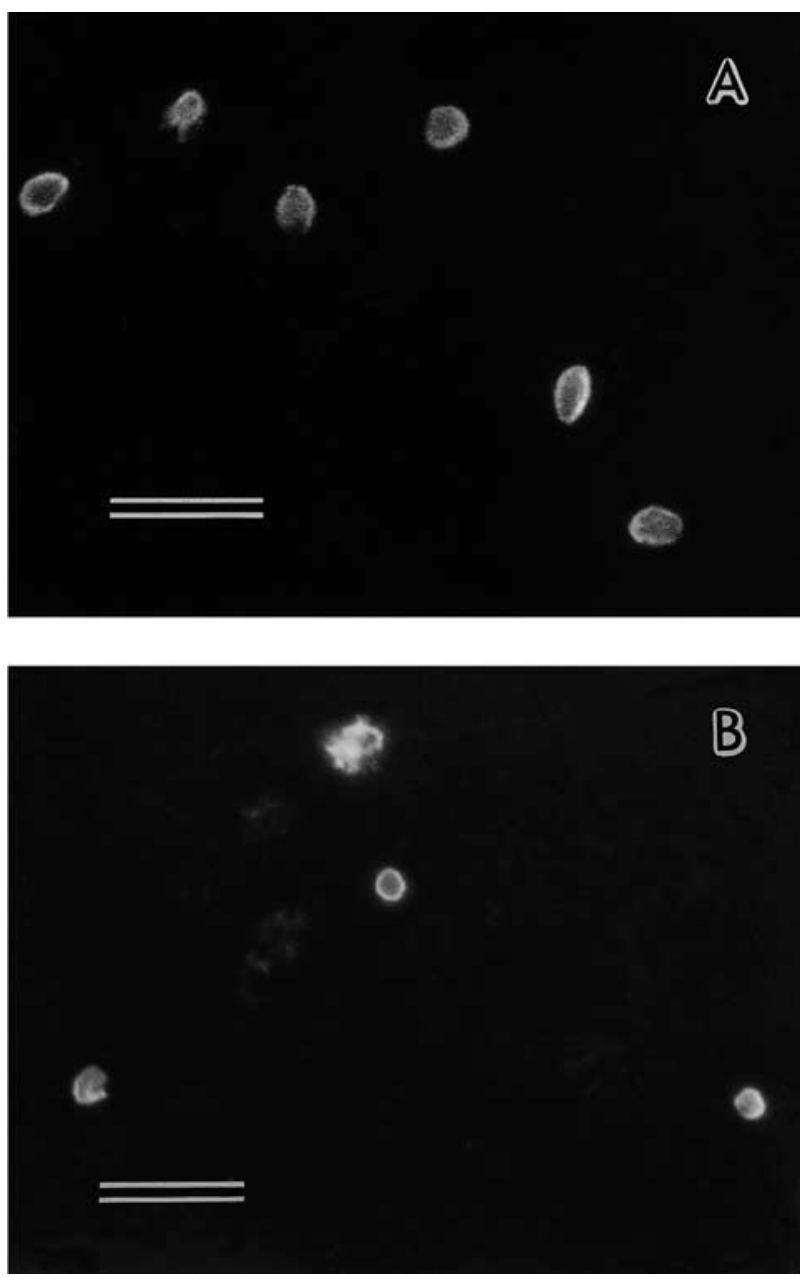

FIGURE 3. Cryptosporidium oocysts stained by a direct immunofluorescent antibody procedure. A, large oocysts from a healthy girl. B, C. parvum oocysts from a patient with diarrhea in Indonesia. Bars $=20 \mu \mathrm{m}$.

Cryptosporidiosis is an emerging disease that poses a serious threat to the people throughout the world. The gravity of cryptosporidiosis in patients with acquired immunodeficiency syndrome and the outbreak of this disease in communities have been reviewed. ${ }^{1}$ Asymptomatic infections have also been detected with increased frequency in many 


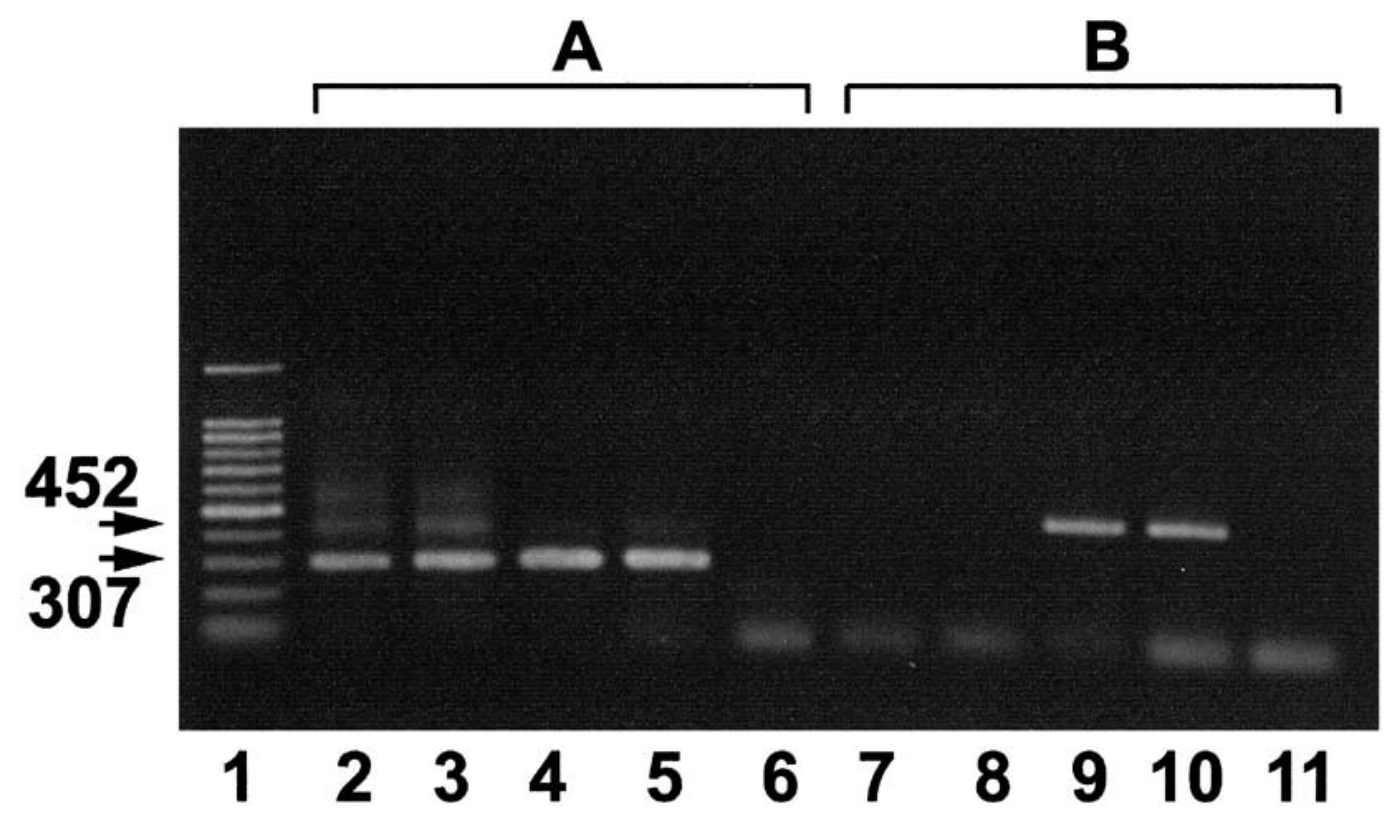

FIGURE 4. Agarose gel electrophoresis of polymerase chain reaction (PCR) products stained with ethidium bromide. Lane 1, 100-basepair DNA ladder (Takara Shuzo Co., Ltd., Osu, Japan). A, PCR products (307 basepairs) obtained with primers specific for the genus Cryptosporidium. Lane 2, C. muris DNA (bovine origin from Japan); lane 3, Cryptosporidium DNA from a healthy girl in Indonesia; lane 4, C. parvum DNA (human origin from Japan); lane 5, C. parvum DNA (human origin from Indonesia); lane 6, negative control. B, PCR products (452 basepairs) obtained with primers specific for C. parvum. Lane 7, C. muris DNA (bovine origin from Japan); lane 8, Cryptosporidium DNA from a healthy girl in Indonesia; lane 9, C. parvum DNA (human origin from Japan); lane 10, C. parvum DNA (human origin from Indonesia); lane 11, negative control. Values on the left are in basepairs.

healthy individuals. ${ }^{2-5}$ Since cryptosporidiosis is a zoonotic disease,${ }^{6}$ the source of human cryptosporidiosis could be some species of parasite that infect mammals, birds, and other animals. ${ }^{3,7,8}$ However, the parasites isolated so far from patients with diarrhea and healthy individuals are exclusively C. parvum.

The present study deals with 2 instances of presumed asymptomatic infection with $C$. muris in Indonesia. We carried out an epidemiologic survey on Cryptosporidium infection in Surabaya, Indonesia from August 1992 to July 1993. Stool specimens of patients with diarrhea (1,174 samples) and healthy individuals $(5,154$ samples) were examined for oocysts of Cryptosporidium. Each stool sample was first subjected to Sheather's sugar flotation and smeared on a slide. The slides were examined by phase-contrast microscopy at $600 \times$ magnification. Once oocysts appearing as phasebright, birefringent bodies containing black residual bodies against a dark background were identified, the remaining concentrated sample was overlaid with saline and stained using the Kinyoun-modified acid-fast technique. The identification of Cryptosporidium was done using taxonomic characteristics, a direct monoclonal antibody immunofluorescent staining method (Crypto-Cel; Cellabs, Brookvale, Australia), which reacts with oocysts of both C. parvum and C. muris, and the polymerase chain reaction (PCR) with primers specific for the genus Cryptosporidium and the primers specific for $C$. parvum. ${ }^{9-11}$ To estimate the oocysts concentration in stool, it was weighed and suspended in water. An aliquot of stool suspension was examined for oocysts by using the Kinyoun-modified acid-fast technique. ${ }^{12}$ The number of oocysts per gram of stool was then calculated from the mean number of oocysts in 3 samples.
Informed consent was obtained from the parents of both girls (see below). The study was approved by the Ethical Committee of the Tropical Disease Research Center of Airlangga University.

The prevalence of $C$. parvum infection has been reported elsewhere. ${ }^{13}$ In addition to subjects in a community who passed oocysts of $C$. parvum, 2 healthy girls (4 and 5 years old) passed oocysts that were morphologically different from those of $C$. parvum. The oocysts were predominantly oval and measured $7.73 \pm 0.17 \times 5.54 \pm 0.12 \mu \mathrm{m}($ mean $\pm \mathrm{SD})$ in 1 case and $7.77 \pm 0.16 \times 5.57 \pm 0.14 \mu \mathrm{m}$ in the other These measurements were equivalent to oocyst dimensions published for the bovine $C$. muris oocysts (mean length $=$ $7.4 \mu \mathrm{m}$, range $=6.6-7.9 \mu \mathrm{m}$, mean width $=5.6 \mathrm{um}$, range $=5.3-6.5 \mu \mathrm{m}){ }^{14}$ They were significantly larger than oocysts of $C$. parvum $(5.0 \times 4.5 \mu \mathrm{m})$ and contained sporozoites and a residue consisting of numerous, small granules (Figures 1 and 2). ${ }^{3}$ They were stained with monoclonal antibody specific for oocysts of Cryptosporidium (Figure 3). When we tested the oocysts by PCR with primers specific for the genus Cryptosporidium, both the specimen containing possible C. muris oocysts and the specimen containing $C$. parvum oocysts were positive. However, when we tested the oocysts by PCR with primers specific for $C$. parvum, the specimen containing $C$. parvum oocysts was positive, but the specimen containing possible $C$. muris oocysts was negative (Figure $4)$. The number of oocysts excreted at the first observation was more than $105 /$ gram of stool. The oocysts were found in stool of 1 girl for 5 days and in the other girl for 6 days. The girls did not complain of any symptoms during the passage of the large oocysts and did not pass C. parvum oocysts.

The oocysts we found in specimens from Surabaya, In- 
donesia closely resembled the oocysts of $C$. muris in terms of the size and morphologic characteristics. These oocysts were well stained by a monoclonal antibody specific for oocysts of both $C$. parvum and $C$. muris. The results of the PCR showed that the oocysts belonged to the genus Cryptosporidium, but were not $C$. parvum. Unfortunately due to the limited amount of field material and infrastructure for animal experiments, the inoculation of oocysts into experimental animals could not be done to confirm the species of the parasite excreted by the 2 girls. However, this study indicates that Cryptosporidium oocysts different from those of C. parvum were excreted in human stool. The present study strongly suggests that infection with $C$. muris occurs in humans.

Acknowledgments: We are indebted to Dr. Yoshiki Aoki, Dr. Hiroji Kanbara (University of Nagasaki, Nagasaki, Japan), and Dr. Motohiro Iseki (Osaka Municipal University, Osaka, Japan) for providing information and advice.

Financial support: This study was supported by the Japan International Cooperation Agency.

Authors' addresses: Tatsuya Katsumata, Department of Parasitology, Institute of Tropical Medicine, Nagasaki University, 1-12-4 Sakamoto, Nagasaki 852-8523, Japan. Daniel Hosea and Ign Gde Ranuh, Tropical Disease Research Center, Airlangga University, JL, Dharmahusada 47, Surabaya, Indonesia. Shoji Uga, Department of Medical Technology, Faculty of Health Science, Kobe University School of Medicine, 7-10-2 Tomogaoka, Sumaku, Kobe 645-0142, Japan. Tetsuo Yanagi, Department of Protozoology, Institute of Tropical Medicine, Nagasaki University, 1-12-4 Sakamoto, Nagasaki 8528523, Japan. Shigeru Kohno, Second Department of Internal Medicine, Nagasaki University School of Medicine, 1-7-1 Sakamoto, Nagasaki 852-8523, Japan.

Reprint requests: Tatsuya Katsumata, Department of Parasitology, Institute of Tropical Medicine, Nagasaki University, 1-12-4 Sakamoto, Nagasaki 852-8523, Japan.

\section{REFERENCES}

1. Griffiths JK, 1998. Human cryptosporidiosis: epidemiology, transmission, clinical disease, treatment, and diagnosis. Adv Parasitol 40: 37-85.

2. Nime FA, Burek JD, Page DL, Holscher MA, Yardley JH, 1976. Acute enterocolitis in a human being infected with the protozoa Cryptosporidium. Gastroenterology 70: 592-598.

3. O'Donoghue PJ, 1995. Cryptosporidium and cryptosporidiosis in man and animals. Int J Parasitol 25: 139-195.

4. Current WL, Garcia LS, 1991. Cryptosporidiosis. Clin Microbiol Rev 4: 325-358.

5. Current WL, Reese NC, Ernst JV, Bailey WS, Heyman MB, Weinstein VVM, 1983. Human cryptosporidiosis in immunocompetent and immunodeficient persons. Studies of an outbreak and experimental transmission. $N$ Engl J Med 308: 1252-1257.

6. Prokopic J, 1983. Cryptosporidiosis-a new zoonosis. Med Parasitol 5: 50-52.

7. Iseki M, Maekawa T, Moriya K, Uni S, Takada S, 1989. Infectivity of Cryptosporidium muris (strain RN 66) in various laboratory animals. Parasitol Res 75: 218-222.

8. Tzipori S, Griffiths JK, 1998. Natural history and biology of Cryptosporidium parvum. Adv Parasitol 40: 5-36.

9. Laxer MA, Timblin BK, Patel RJ, 1991. DNA sequences for the specific detection of Cryptosporidium parvum by the polymerase chain reaction. Am J Trop Med Hyg 45: 688-694.

10. Rochelle PA, Leon RD, Stewart MH, Wolfe RL, 1997. Comparison of primers and optimization of PCR conditions for detection of Cryptosporidium parvum and Giardia lamblia in water. Appl Environ Microbiol 63: 106-114.

11. Rochelle PA, Ferguson DM, Handojo TJ, Leon RD, Stewart MH, Wolfe RL, 1997. An assay combining cell culture with reverse transcriptase PCR to detect and determine the infectivity of waterborne Cryptosporidium parvum. Appl Environ Microbiol 63: 2029-2037.

12. Ma P, Soave R, 1983. Three-step stool examination for cryptosporidiosis in 10 homosexual men with protracted watery diarrhea. J Infect Dis 147: 824-828.

13. Katsumata T, Hosea D, Wasito EB, Kohno S, Kohei H, Soeparto P, Ranuh IG, 1998. Cryptosporidiosis in Indonesia: a hospitalbased study and a community-based survey. Am J Trop Med Hyg 59: 628-632.

14. Upton SJ, Current WL, 1985. The species of Cryptosporidium (Apicomplexa: Cryptosporidiidae) infecting mammals. J Parasitol 71: 625-629. 